They include increasing medical school enrolment; offering incentives to retain physicians and rural doctors; temporarily increasing the number of fully qualified international medical graduates; and eliminating physician billing caps and regulations mandating forced retirement. — Laura Eggertson, $C M A J$

DOI:IO.I503/cmaj.051582

\section{Tsunami donations help}

\section{worldwide}

Published at www.cmaj.ca on Dec. 27, 2005. Revised on Jan. 5, 2006.

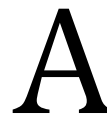
year after the tsunami that devastated Southeast Asia, Médecins Sans Frontières (MSF) reports that donors' generosity helped not only victims of that disaster, but other crises worldwide.

Donors gave \$150 million to MSF's I9 branches worldwide, including \$2.7 million to MSF Canada for emergency aid after the tsunami. It was the largest financial support the organization has received in its 30-year history, said Patrice Pagé, then executive director of MSF Canada.

Less than 2 weeks after the tsunami struck on Dec. 26, 2004, MSF made the "controversial" decision to tell donors it had received enough money - \$25 million at that point - to finance its tsunami relief operations.

Instead of refusing further donations, MSF asked for unrestricted funds to go to other emergencies, including nutritional crises in Africa.

The experiment worked; less than $\mathrm{I} \%$ of donors insisted that their money be used only for tsunami relief and the rest allowed it to go into MSF's emergency relief fund.

MSF's decision to tell donors early on that they had enough for tsunami aid was "a good idea," says Dane Rowlands, associate director of the Norman Patterson School of International Development at Ottawa's Carleton University. "It allows them enough flexibility that hopefully they will be

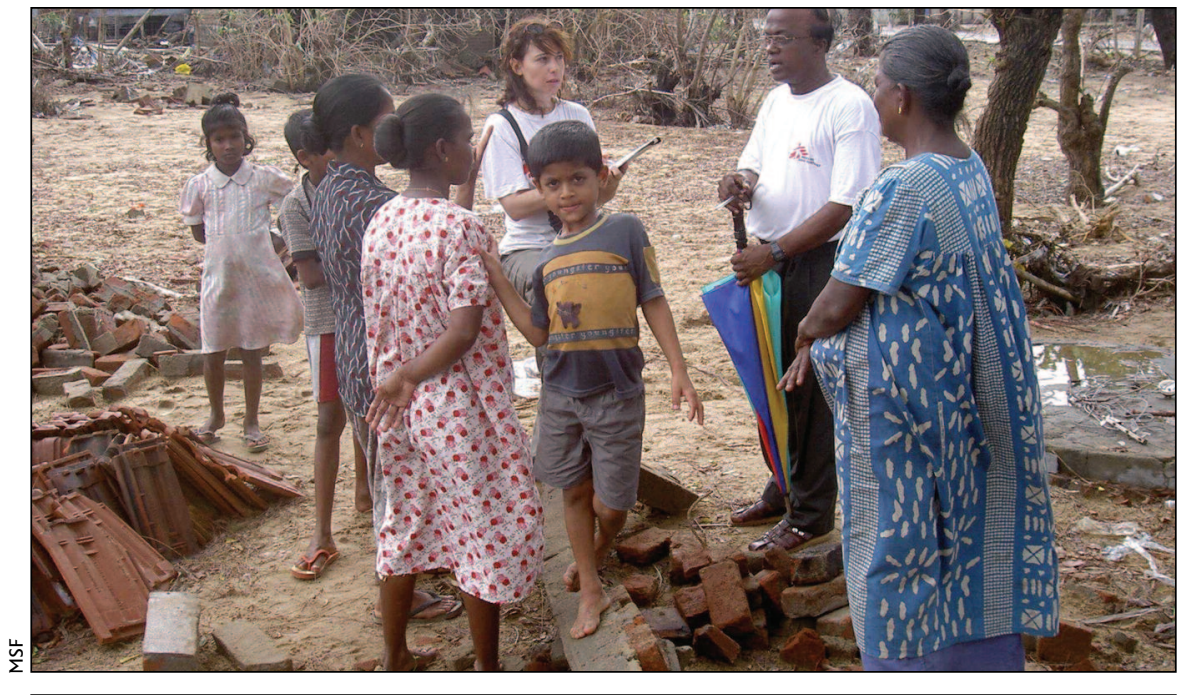

A mental health survey of displaced people in Aceh found $83 \%$ were affected by severe emotional distress.

able to make a resource allocation to less public, but high areas of need."

MSF channelled \$1.9 million of the Canadian tsunami donations to its emergency fund. That money enabled the organization to set up operations 48 hours after an earthquake devastated the Kashmir region of Pakistan on Oct. 8. MSF Canada spent just under $\$ 2$ million responding to the earthquake and \$r.6 million in providing emergency assistance in the Congo. The organization also sent teams and assistance to Darfur, Sudan, to Chad, and to Niger, where by the end of the year MSF expects to have treated more than 50 ooo undernourished children.

MSF's account of how it spent its money was also important, says Rowlands. Over the years, NGOs have demanded that other institutions be more transparent, now that demand is being made of them.

In responding to the tsunami, which killed an estimated 300 ooo people, MSF focused its efforts in Aceh, Indonesia. By the end of 2006, the organization will have spent $\$ 800$ ooo of the Canadian contributions on its Aceh operations.

Initially, MSF concentrated on primary health care, including vaccinations and tetanus shots, and supplied nurses and other medical staff to the public health structure to replace hundreds of health workers who died.

Now the organization is concentrating on mental health consultations.
"People are still deeply affected, not only by the consequences of the tsunami, but also because of the consequences of the [civil] conflict there," says Pagé. — Laura Eggertson, CMAJ

DOI:I0.1503/cmaj.051642

\section{Wait-time benchmarks}

\section{fall short}

$\mathrm{N}$ ew wait-time benchmarks announced Dec. 12 by the federal government were both lauded as a major shift in health care delivery and criticized for failing to set deadlines for implementation.

The announcement fulfils a promise made in the September 2004 federal/ provincial health accord to establish "evidence-based wait-time benchmarks" in 5 areas of care. The benchmark targets in all jurisdictions (except Quebec, which will develop its own plan) include: cancer radiation treatment within 4 weeks, hip fracture repair within 48 hours, hip and knee replacement surgery within 6 months, cataract surgery within 4 months for high-risk patients, breast cancer screening for women 50 to 69 every 2 years, cervical cancer screening for women I8 to 69 every 3 years; and cardiac bypass surgery within 2 to 6 weeks for those at high risk. 